\title{
The gap in postoperative outcome between older and younger patients with stage I-III colorectal cancer has been bridged; results from the Netherlands cancer registry
}

Citation for published version (APA):

Brouwer, N. P. M., Heil, T. C., Rikkert, M. G. M. O., Lemmens, V. E. P. P., Rutten, H. J. T., de Wilt, J. H. W., \& van Erning, F. N. (2019). The gap in postoperative outcome between older and younger patients with stage I-III colorectal cancer has been bridged; results from the Netherlands cancer registry. European Journal of Cancer, 116, 1-9. https://doi.org/10.1016/j.ejca.2019.04.036

Document status and date:

Published: 01/07/2019

DOI:

10.1016/j.ejca.2019.04.036

Document Version:

Publisher's PDF, also known as Version of record

Document license:

Taverne

Please check the document version of this publication:

- A submitted manuscript is the version of the article upon submission and before peer-review. There can be important differences between the submitted version and the official published version of record. People interested in the research are advised to contact the author for the final version of the publication, or visit the DOI to the publisher's website.

- The final author version and the galley proof are versions of the publication after peer review.

- The final published version features the final layout of the paper including the volume, issue and page numbers.

Link to publication

\footnotetext{
General rights rights.

- You may freely distribute the URL identifying the publication in the public portal. please follow below link for the End User Agreement:

www.umlib.nl/taverne-license

Take down policy

If you believe that this document breaches copyright please contact us at:

repository@maastrichtuniversity.nl

providing details and we will investigate your claim.
}

Copyright and moral rights for the publications made accessible in the public portal are retained by the authors and/or other copyright owners and it is a condition of accessing publications that users recognise and abide by the legal requirements associated with these

- Users may download and print one copy of any publication from the public portal for the purpose of private study or research.

- You may not further distribute the material or use it for any profit-making activity or commercial gain

If the publication is distributed under the terms of Article 25fa of the Dutch Copyright Act, indicated by the "Taverne" license above, 


\title{
The gap in postoperative outcome between older and younger patients with stage I-III colorectal cancer has been bridged; results from the Netherlands cancer registry
}

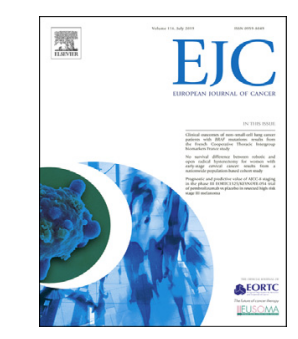

\author{
Nelleke P.M. Brouwer ${ }^{\mathrm{a}, *}$, Thea C. Heil ${ }^{\mathrm{b}}$, Marcel G.M. Olde Rikkert ${ }^{\mathrm{b}}$, \\ Valery E.P.P. Lemmens ${ }^{\text {c,d }}$, Harm J.T. Rutten ${ }^{\text {e,f }}$, Johannes H.W. de Wilt ${ }^{\text {a }}$, \\ Felice N. van Erning ${ }^{\mathrm{C}}$
}

\footnotetext{
a Department of Surgery, Radboud University Medical Center, Geert Grooteplein Zuid 10, 6525 GA, Nijmegen, the Netherlands

${ }^{\mathrm{b}}$ Department of Geriatrics, Radboud University Medical Center, Geert Grooteplein Zuid 10, 6525 GA, Nijmegen, the Netherlands

${ }^{\mathrm{c}}$ Department of Research, Netherlands Comprehensive Cancer Organization (IKNL), Godebaldkwartier 419, 3511 DT, Utrecht, the Netherlands

${ }^{\mathrm{d}}$ Department of Public Health, Erasmus University Medical Center, Doctor Molewaterplein 30, 3015 GD, Rotterdam, the Netherlands

e Department of Surgery, Catharina Hospital, Michelangelolaan 2, 5623 EJ, Eindhoven, the Netherlands

${ }^{\mathrm{f}}$ Department of Surgery, Maastricht University Medical Center, P. Debyelaan 25, 6229 HX, Maastricht, the Netherlands
}

Received 10 March 2019; received in revised form 22 April 2019; accepted 27 April 2019

Available online 1 June 2019

\section{KEYWORDS \\ Aged; \\ Netherlands/ \\ epidemiology; \\ Rectal neoplasms/ \\ mortality; \\ Rectal neoplasms/ \\ surgery; \\ Colonic neoplasms/ \\ mortality; \\ Colonic neoplasms/}

\begin{abstract}
Aim of the study: Previous studies have shown that older patients benefited less than younger patients from surgical treatment for colorectal cancer (CRC). However, CRC care has advanced over time, and it is time to assess whether the difference in postoperative mortality between older and younger CRC patients is still present.

Methods: Patients with primary stage I-III CRC diagnosed between 2005 and 2016 were selected from the Netherlands Cancer Registry $(\mathrm{N}=111,778)$. Trends in postoperative mortality and 1-year postoperative relative survival (RS) were analysed, stratified according to age ( $<75$ versus $\geq 75$ years) and tumour location (colon versus rectum). One-year postoperative RS was analysed to correct for background mortality in the older population.

Results: Between 2005 and 2016, 30-day postoperative mortality showed a stronger decrease for older patients (from $10.0 \%$ to $4.0 \%$ for colon cancer [p $<0.001$ ] and from $8.3 \%$ to $2.7 \%$
\end{abstract}

* Corresponding author: Department of Surgery, Radboud University Medical Center, Geert Grooteplein Zuid 10, 6525 GA, Nijmegen, the Netherlands. Fax: +31243635115

E-mail addresses: nelleke.brouwer@radboudumc.nl (N.P.M. Brouwer), thea.heil@radboudumc.nl (T.C. Heil), marcel.olderikkert@ radboudumc.nl (M.G.M. Olde Rikkert), v.lemmens@iknl.nl (V.E.P.P. Lemmens), harm.rutten@catharinaziekenhuis.nl (H.J.T. Rutten), hans. dewilt@radboudumc.nl (J.H.W. de Wilt), f.vanerning@iknl.nl (F.N. van Erning). 
surgery;

Colorectal neoplasms;

Postoperative

mortality for rectal cancer $[\mathrm{p}<0.001]$ ) compared with younger patients (from $2.0 \%$ to $0.9 \%$ for colon cancer $[\mathrm{p}<0.001]$ and from $1.4 \%$ to $0.7 \%$ for rectal cancer $[\mathrm{p}=0.01])$. Between 2005 and 2016, also 1-year RS increased more for older patients (from $84.8 \%$ to $94.6 \%$ for colon cancer and from $86.1 \%$ to $97.2 \%$ for rectal cancer) compared with younger patients (from $94.0 \%$ to $97.8 \%$ for colon cancer and from $96.3 \%$ to $98.8 \%$ for rectal cancer).

Conclusion: Between 2005 and 2016, differences in postoperative mortality between older and younger CRC patients decreased. One-year postoperative RS was almost equal for older and younger patients in 2015-2016. This information is crucial for shared decision-making on surgical treatment.

(C) 2019 Elsevier Ltd. All rights reserved.

\section{Introduction}

With over $50 \%$ of colorectal cancer (CRC) cases occurring in those over the age of 70 years, CRC is a disease of older patients [1]. Given the aging of Western societies, the number of older CRC patients will increase even further in the coming decades.

The older CRC population has great variety among their individual health statuses, with comorbidities mainly developing in those between 70 and 75 years of age [2]. This matter results in a population that includes patients who experience increased disabilities and comorbidities, patients with excellent health status and many in between these extremes.

The heterogeneity of the older population and the lack of specific data on older patients, because of their underrepresentation in clinical trials [3], make it difficult to establish treatment strategies. For CRC patients without distant metastases, surgical resection is the best option for curative treatment, and improvements in perioperative care, surgical techniques and the introduction of multimodality treatment have made surgery feasible for the majority of patients. However, there seems to be a tendency to offer surgical resection less in older compared with younger patients $[4,5]$. This reservations can be explained by previous studies, which state that older patients benefit less from surgical treatment for $\mathrm{CRC}$ as reflected in the higher postoperative morbidity and mortality rates after surgical resection $[6,7]$. Owing to these inferior outcomes in older patients, there has been an increasing focus on their frailty, i.e. their state of increased vulnerability and the incorporation of geriatric assessment in the oncology treatment decision-making $[8,9]$.

However, surgical treatment of CRC patients has advanced with improved surgical techniques (e.g. minimally invasive surgery), subspecialisation and better perioperative care, in efforts to decrease postoperative mortality rates. Information on present-day postoperative mortality rates of older patients is important for shared decision-making regarding surgical treatment. Therefore, the aim of the present study is to investigate trends in postoperative mortality over time and to assess whether the difference in postoperative mortality between younger and older CRC patients is still present in the current practice.

\section{Methods}

\subsection{Data collection}

In the Netherlands, all newly diagnosed malignancies are registered by the Netherlands Cancer Registry (NCR). The NCR mainly receives notification from the Dutch pathology reporting system, and the National Registry of Hospital Discharge Diagnoses completes case ascertainment. Trained registry personnel gather data on patient, tumour and treatment characteristics directly from the medical records, following notification.

From the NCR, patients with stage I-III CRC who were diagnosed between 2005 and 2016 were selected for our study $(\mathrm{N}=111,778)$. The anatomical subsite of a tumour was coded according to the International Classification of Diseases for Oncology [10]. The tumournode-metastasis (TNM) classification was used for stage notification of the primary tumour, according to the edition valid at the time of the cancer diagnosis [11]. Pathological TNM staging took precedence over clinical staging, except in the case of missing pathological data ( $0.5 \%$ of patients).

The study period was divided into 6 time periods of 2 years each (2005-2006, 2007-2008, 2009-2010, 2011-2012, 2013-2014 and 2015-2016). Patients were stratified according to tumour localisation and age, specifically colon and rectum (rectosigmoid and rectum) as well as younger patients ( $0-74$ years of age) and older patients $(\geq 75$ years), respectively. The age of 75 years and above was chosen to define older patients, as the prevalence of multimorbidity increases with age and more than $50 \%$ of the people aged 75 years and older suffer from at least two chronic diseases $[12,13]$.

Patients' survival status was obtained by linking the NCR to the Municipal Personal Records Database, which records information on their inhabitants' vital 
status. For all patients, a follow-up was completed at least 1 year after surgery.

\subsection{Statistical analyses}

Patients were stratified according to age group and primary tumour localisation, and only patients who underwent resection, with exception of patients who underwent local excision (e.g. polypectomy or TEM), were included $(\mathrm{N}=104,185)$. Data on patient and tumour characteristics were analysed, and the significance of differences in their characteristics was analysed using the $\chi^{2}$ test.

Crude 30-day mortality rates were analysed. Because previous studies showed that 30-day mortality highly underestimates the risk of dying in the first year after surgery [14], crude postoperative mortality rates for 90day and 1-year mortality were reported as well. Multivariable logistic regression analyses were applied to estimate odds ratios (ORs) with $95 \%$ confidence intervals (CIs) to determine the association between time period and postoperative mortality. Besides the period of diagnosis, the variables included in the model are gender, tumour-stage, subsite of the tumour (colon cancer), histology, social economic status and the administration of chemotherapy (colon cancer) or radiotherapy (rectal cancer).

To estimate cancer-specific survival, 1-year relative survival (RS) was calculated. We define 1-year RS as the ratio of the absolute survival observed among the cancer patients and the survival that would have been expected for a comparable group from the general population (same age, gender and period).[15] Expected survival was calculated from population life tables from the Netherlands. Next, to analyse whether changes in 1-year RS estimates were because of changes in acute or subacute mortality, conditional 1-year RS was calculated, on the condition of being alive 30 or 90 days after resection.

For patients with multiple dates of resection, the last date of resection was included for RS and multivariable logistic regression analyses. For patients with multiple resections on the same date, the tumour with the most advanced TNM-stage was used for these analyses.

For analyses on surgical resection rates, all patients with stage I-III CRC were included, with the exception of patients who underwent local excision. The trends over time for the proportions of patients undergoing surgical resection were reported for the different time periods, and the Cochrane Armitage trend test was used to analyse the significance of trends over time. Trends over time for surgical resection rates stratified according to the presence or absence of comorbidities were added as Supplementary figures.

$\mathrm{P}$ values below 0.05 were considered statistically significant. Analysis was performed using SAS/STAT ${ }^{\circledR}$ statistical software (SAS system 9.4, SAS Institute,
Cary, NC) and SPSS Statistics for Windows (version 22.0, IBM Corp, Armonk, NY).

\section{Results}

Between 2005 and 2016, 111,778 stage I-III CRC patients were diagnosed, of whom 104,185 (93.2\%) underwent resection. 73,065 were colon cancer patients and 31,120 were rectal cancer patients.

The characteristics of patients who underwent resection are shown in Table 1. For colon cancer patients, the proportion of stage I tumours increased. The proportion of elective surgical procedures remained between 91 and $93 \%$ for both age groups. The use of a laparoscopic surgical approach in colon cancer patients increased between 2009 and 2016, specifically from $30 \%$ to $71 \%$ for younger patients and from $23 \%$ to $61 \%$ for older patients. For rectal and colon cancer patients, similar trends over time were demonstrated, but with an even larger increase in the use of laparoscopic approach for rectal cancer patients.

\subsection{Postoperative mortality}

30-day postoperative mortality decreased from $2.0 \%$ to $0.9 \%$ for younger colon cancer patients and from $1.4 \%$ to $0.7 \%$ for younger rectal cancer patients. A larger decrease in mortality was seen for older patients from $10.0 \%$ to $4.0 \%$ for colon cancer and from $8.3 \%$ to $2.7 \%$ for rectal cancer (Fig. 1).

The odds of dying within 30 days, 90 days or 1 year decreased significantly from 2005-2006 to 2015-2016 (Table 2). For 30-day mortality for colon cancer, ORs amounted to $0.48(95 \% \mathrm{CI} 0.36-0.64)$ for younger patients and $0.38(95 \%$ CI $0.32-0.46)$ for older patients. For those with rectal cancer, ORs were found to be 0.50 $(95 \%$ CI $0.32-0.79)$ for younger patients and $0.30(95 \%$ CI $0.20-0.44)$ for older patients. Similar trends were found for 90-day and 1-year mortality.

\subsection{One-year relative survival}

Between 2005 and 2016, 1-year RS increased for both younger as well as older CRC patients (Fig. 2A). For younger patients, the 1-year RS increased from $94.0 \%$ to $97.8 \%$ for those with colon cancer and from $96.3 \%$ to $98.8 \%$ for those with rectal cancer. For older patients, a larger increase in 1-year RS was demonstrated. The 1year RS increased from $84.8 \%$ to $94.6 \%$ for the older patients with colon cancer and from $86.1 \%$ to $97.2 \%$ for the older patients with rectal cancer.

\subsection{Conditional relative survival}

When the acute postoperative mortality (within 30 days) was excluded, the increase in survival between 2005 and 2016 was most pronounced for the older patients. An 
Table 1

Patient, tumour and treatment characteristics of all patients diagnosed with stage I-III CRC between 2005 and 2016 who underwent resection by period of diagnosis. Patients were stratified according to age ( $<75$ years or $\geq 75$ years) and primary tumour location (colon or rectum).

\begin{tabular}{|c|c|c|c|c|c|c|c|c|c|c|c|c|}
\hline \multirow{3}{*}{$\begin{array}{l}\text { Patient/tumour characteristics } \\
\text { Colon, }<75 \text { years } \\
\text { Gender }\end{array}$} & \multicolumn{12}{|c|}{$\underline{\text { Period of diagnosis }}$} \\
\hline & \multicolumn{2}{|c|}{$2005-2006$} & \multicolumn{2}{|c|}{$2007-2008$} & \multicolumn{2}{|c|}{$2009-2010$} & \multicolumn{2}{|c|}{$2011-2012$} & \multicolumn{2}{|c|}{ 2013-2014 } & \multicolumn{2}{|c|}{$2015-2016$} \\
\hline & & & & & & & & & & & & \\
\hline Male & 3101 & $(54)$ & 3220 & (54) & 3427 & (54) & 3747 & (54) & 4119 & $(55)$ & 5629 & $(56)$ \\
\hline Female & 2617 & $(46)$ & 2794 & (46) & 2974 & (46) & 3214 & (46) & 3387 & (45) & 4456 & (44) \\
\hline \multicolumn{13}{|l|}{ Stage } \\
\hline Stage I & 1042 & (18) & 1045 & (17) & 1153 & (18) & 1350 & (19) & 1588 & $(21)$ & 3061 & (30) \\
\hline Stage II & 2507 & (44) & 2555 & $(42)$ & 2677 & $(42)$ & 2798 & $(40)$ & 3004 & $(40)$ & 3418 & (34) \\
\hline Stage III & 2169 & $(38)$ & 2414 & $(40)$ & 2571 & $(40)$ & 2813 & $(40)$ & 2914 & (39) & 3606 & (36) \\
\hline \multicolumn{13}{|l|}{ Histology } \\
\hline Adenocarcinoma & 4801 & (84) & 5032 & (84) & 5382 & (84) & 6000 & (86) & 6648 & (89) & 9113 & $(90)$ \\
\hline Mucinous adenocarcinoma & 868 & (15) & 903 & (15) & 931 & (15) & 902 & (13) & 779 & (10) & 888 & (9) \\
\hline Signet ring cell & 49 & (1) & 79 & (1) & 88 & (1) & 59 & (1) & 79 & (1) & 84 & (1) \\
\hline \multicolumn{13}{|l|}{ Sublocalisation } \\
\hline Proximal colon & 2742 & $(48)$ & 2909 & (48) & 3101 & $(48)$ & 3355 & $(48)$ & 3459 & (46) & 4494 & $(45)$ \\
\hline Distal colon & 2867 & $(50)$ & 3007 & $(50)$ & 3194 & $(50)$ & 3456 & $(50)$ & 3826 & $(51)$ & 5462 & $(54)$ \\
\hline Overlapping localisation & 72 & (1) & 68 & (1) & 49 & (1) & 77 & (1) & 168 & (2) & 44 & $(0)$ \\
\hline Colon, not otherwise specified & 37 & (1) & 30 & $(0)$ & 57 & (1) & 73 & (1) & 53 & (1) & 85 & (1) \\
\hline Social economic status & & & & & & & & & & & & \\
\hline Low & 1435 & $(25)$ & 1560 & (26) & 2109 & (33) & 2234 & (32) & 2014 & $(27)$ & 2870 & $(28)$ \\
\hline Medium & 2610 & (46) & 2661 & (44) & 2302 & (36) & 2541 & (37) & 2748 & (37) & 4039 & $(40)$ \\
\hline High & 1651 & (29) & 1753 & (29) & 1953 & (31) & 2145 & (31) & 2718 & (36) & 3138 & (31) \\
\hline Unknown & 22 & $(0)$ & 40 & (1) & 37 & (1) & 41 & (1) & 26 & $(0)$ & 38 & $(0)$ \\
\hline (Neo)adjuvant chemotherapy & & & & & & & & & & & & \\
\hline Yes & 2068 & $(36)$ & 2351 & (39) & 2528 & (39) & 2722 & (39) & 2862 & $(38)$ & 3424 & (34) \\
\hline No & 3650 & (64) & 3663 & (61) & 3873 & (61) & 4239 & $(61)$ & 4644 & $(62)$ & 6661 & (66) \\
\hline Urgency $^{\mathrm{a}}$ & & & & & & & & & & & & \\
\hline No, elective & & & & & 5806 & $(91)$ & 6313 & $(91)$ & 6826 & $(91)$ & 9377 & (93) \\
\hline Yes, emergency surgery & & & & & 468 & (7) & 525 & (8) & 523 & (7) & 494 & (5) \\
\hline Construction stent/stoma, followed by planned surgery & & & & & 36 & (1) & 39 & (1) & 65 & (1) & 37 & $(0)$ \\
\hline Not applicable & & & & & 33 & (1) & 23 & $(0)$ & 31 & $(0)$ & 0 & $(0)$ \\
\hline Unknown & & & & & 58 & (1) & 61 & (1) & 61 & (1) & 177 & (2) \\
\hline Approach $^{\mathrm{b}}$ & & & & & & & & & & & & \\
\hline Laparoscopic surgery & & & & & 1931 & $(30)$ & 2903 & $(42)$ & 4221 & $(56)$ & 7204 & $(71)$ \\
\hline Laparoscopic surgery with conversion & & & & & 460 & (7) & 574 & (8) & 637 & (8) & 845 & (8) \\
\hline Open surgery & & & & & 3945 & $(62)$ & 3430 & (49) & 2564 & (34) & 1996 & (20) \\
\hline Not applicable & & & & & 15 & $(0)$ & 11 & $(0)$ & 15 & $(0)$ & 0 & $(0)$ \\
\hline Unknown & & & & & 4 & (1) & 43 & (1) & 69 & (1) & 40 & $(0)$ \\
\hline Colon, $\geq 75$ years & & & & & & & & & & & & \\
\hline Gender & & & & & & & & & & & & \\
\hline Male & 1740 & (44) & 2019 & $(45)$ & 2182 & (47) & 2218 & (46) & 2536 & (49) & 2388 & $(50)$ \\
\hline Female & 2260 & $(57)$ & 2445 & $(55)$ & 2507 & $(53)$ & 2576 & (54) & 2632 & $(51)$ & 2421 & $(50)$ \\
\hline Stage & & & & & & & & & & & & \\
\hline Stage I & 719 & (18) & 776 & (17) & 857 & (18) & 911 & (19) & 1182 & (23) & 1003 & $(21)$ \\
\hline Stage II & 1975 & $(49)$ & 2128 & (48) & 2298 & (49) & 2275 & (47) & 2233 & (43) & 2229 & (46) \\
\hline Stage III & 1306 & (33) & 1560 & (35) & 1534 & (33) & 1608 & (34) & 1753 & (34) & 1577 & (33) \\
\hline Histology & & & & & & & & & & & & \\
\hline Adenocarcinoma & 3265 & $(82)$ & 3675 & $(82)$ & 3843 & $(82)$ & 4080 & $(85)$ & 4468 & $(86)$ & 4191 & $(87)$ \\
\hline Mucinous adenocarcinoma & 686 & (17) & 743 & (17) & 784 & (17) & 657 & (14) & 644 & (12) & 561 & (12) \\
\hline Signet ring cell & 49 & (1) & 46 & (1) & 62 & (1) & 57 & (1) & 56 & (1) & 57 & (1) \\
\hline Sublocalisation & & & & & & & & & & & & \\
\hline Proximal colon & 2361 & $(59)$ & 2623 & $(59)$ & 2758 & $(59)$ & 2779 & $(58)$ & 2873 & $(56)$ & 2901 & $(60)$ \\
\hline Distal colon & 1561 & (39) & 1762 & (39) & 1870 & (40) & 1922 & $(40)$ & 2121 & (41) & 1855 & (39) \\
\hline Overlapping localisation & 48 & (1) & 45 & (1) & 33 & (1) & 48 & (1) & 135 & (3) & 22 & $(0)$ \\
\hline Colon, not otherwise specified & 30 & (1) & 34 & (1) & 28 & (1) & 45 & (1) & 39 & (1) & 31 & (1) \\
\hline Social economic status & & & & & & & & & & & & \\
\hline Low & 1172 & (29) & 1221 & (27) & 1695 & (36) & 1776 & (37) & 1581 & (31) & 1528 & (32) \\
\hline Medium & 1736 & (43) & 1993 & (45) & 1693 & (36) & 1716 & (36) & 1883 & (36) & 1856 & (39) \\
\hline High & 1079 & (27) & 1243 & (28) & 1287 & (27) & 1294 & (27) & 1685 & (33) & 1408 & (29) \\
\hline Unknown & 13 & (0) & 7 & (0) & 14 & (0) & 8 & (0) & 19 & (0) & 17 & (0) \\
\hline (Neo)adjuvant c & & & & & & & & & & & & \\
\hline Yes & 279 & (7) & 380 & (9) & 385 & (8) & 454 & (9) & 564 & (11) & 510 & (11) \\
\hline
\end{tabular}


Table 1 (continued)

\begin{tabular}{|c|c|c|c|c|c|c|c|c|c|c|c|c|c|c|}
\hline \multirow{3}{*}{$\begin{array}{l}\text { Patient/tumour characteristics } \\
\text { No }\end{array}$} & & & \multicolumn{12}{|c|}{ Period of diagnosis } \\
\hline & & & \multicolumn{2}{|c|}{$2005-2006$} & \multicolumn{2}{|c|}{$2007-2008$} & \multicolumn{2}{|c|}{$2009-2010$} & \multicolumn{2}{|c|}{$2011-2012$} & \multicolumn{2}{|c|}{$2013-2014$} & \multicolumn{2}{|c|}{$2015-2016$} \\
\hline & & & 3721 & (93) 4 & 4084 & $(91)$ & 4304 & $(92)$ & 4340 & $(91)$ & 4604 & (8)9 & 4299 & (89) \\
\hline \multicolumn{15}{|l|}{ Urgency $^{\mathrm{a}}$} \\
\hline No, elective & & & & & & & 4237 & $(90)$ & 4376 & $(91)$ & 4688 & (91) & 4387 & (91) \\
\hline Yes, emergency surgery & & & & & & & 367 & (8) & 324 & (7) & 393 & (8) & 362 & (8) \\
\hline Construction stent/stoma, followed by & anned st & gery & & & & & 28 & (1) & 24 & (1) & 32 & (1) & 17 & $(0)$ \\
\hline Not applicable & & & & & & & 21 & $(0)$ & 29 & (1) & 18 & $(0)$ & 0 & (0) \\
\hline Unknown & & & & & & & 36 & (1) & 41 & (1) & 37 & (1) & 43 & (1) \\
\hline \multicolumn{15}{|l|}{ Approach $^{\mathrm{b}}$} \\
\hline Laparoscopic surgery & & & & & & & 1096 & $(23)$ & 1574 & (33) & 2525 & (49) & 2940 & (61) \\
\hline Laparoscopic surgery with conversion & & & & & & & 296 & (6) & 336 & (7) & 456 & (9) & 454 & (9) \\
\hline Open surgery & & & & & & & 3255 & (69) & 2836 & (59) & 2142 & (41) & 1401 & (29) \\
\hline Not applicable & & & & & & & 14 & (0) & 18 & (0) & 14 & (0) & 0 & (0) \\
\hline Unknown & & & & & & & 28 & (1) & 30 & (1) & 31 & (1) & 14 & (0) \\
\hline & Period & f diag & nosis & & & & & & & & & & & \\
\hline & $2005-$ & & 2007 & -2008 & & $2009-20$ & 10 & $2011-$ & 2012 & & $13-2014$ & & $2015-2$ & 016 \\
\hline Rectum, $<75$ years & & & & & & & & & & & & & & \\
\hline Gender & & & & & & & & & & & & & & \\
\hline Male & 2346 & (66) & 2289 & (63) & & 2192 & (64) & 2239 & (64) & & 46 & (66) & 2868 & (65) \\
\hline Female & 1192 & (34) & 1327 & (37) & & 249 & (36) & 1269 & (36) & & 92 & (34) & 1553 & (35) \\
\hline Stage & & & & & & & & & & & & & & \\
\hline Stage I & 1077 & (30) & 1153 & (32) & & 153 & (34) & 1207 & (34) & 12 & 79 & (36) & 1058 & (24) \\
\hline Stage II & 1121 & (32) & 1105 & (31) & & 024 & (30) & 957 & (27) & & 17 & (29) & 911 & (21) \\
\hline Stage III & 1323 & (38) & 1358 & (38) & & 264 & (37) & 1344 & (38) & & 42 & (35) & 2452 & (55) \\
\hline Histology & & & & & & & & & & & & & & \\
\hline Adenocarcinoma & 3212 & (91) & 3294 & (91) & & 127 & (91) & 3246 & (93) & 32 & 98 & (93) & 4194 & (95) \\
\hline Mucinous adenocarcinoma & 291 & (8) & 303 & (8) & & 296 & (9) & 247 & (7) & 22 & & (6) & 207 & (5) \\
\hline Signet ring cell & 18 & (1) & 19 & (1) & & 18 & (1) & 15 & (0) & 20 & & (1) & 20 & (0) \\
\hline Social economic status & & & & & & & & & & & & & & \\
\hline Low & 885 & (25) & 896 & (25) & & 106 & $(32)$ & 1121 & (32) & 92 & & (26) & 1233 & (28) \\
\hline Medium & 1609 & (46) & 1675 & (46) & & 313 & (38) & 1318 & (38) & & 42 & (38) & 1860 & (42) \\
\hline High & 1006 & (29) & 1022 & (28) & & 003 & (29) & 1048 & (30) & & 67 & (36) & 1305 & (30) \\
\hline Unknown & 21 & (1) & 23 & (1) & 19 & 9 & (1) & 21 & (1) & 8 & & (0) & 23 & (1) \\
\hline (Neo)adjuvant radiotherapy & & & & & & & & & & & & & & \\
\hline Yes & 2305 & $(65)$ & 2258 & (62) & & 2142 & $(62)$ & 1944 & (55) & & 46 & (44) & 2672 & $(60)$ \\
\hline No & 1216 & (35) & 1358 & (38) & & 299 & (38) & 1564 & (45) & 19 & 92 & (56) & 1749 & (40) \\
\hline Approach $^{\mathrm{b}}$ & & & & & & & & & & & & & & \\
\hline Laparoscopic surgery & & & & & & 007 & (29) & 1610 & (46) & & 14 & (65) & 3568 & $(81)$ \\
\hline Laparoscopic surgery with conversion & & & & & & 207 & (6) & 266 & (8) & 29 & 2 & (8) & 290 & (7) \\
\hline Open surgery & & & & & & 2184 & (63) & 1571 & (45) & 88 & & (25) & 561 & (13) \\
\hline Not applicable & & & & & 5 & 5 & $(0)$ & 14 & (0) & 5 & & (0) & 0 & (0) \\
\hline Unknown & & & & & & 38 & (1) & 47 & (1) & 40 & & (1) & 2 & (0) \\
\hline Rectum, $\geq 75$ years & & & & & & & & & & & & & & \\
\hline Gender & & & & & & & & & & & & & & \\
\hline Male & 758 & (54) & 761 & (54) & & 748 & (55) & 756 & (57) & 78 & & (58) & 746 & $(60)$ \\
\hline Female & 656 & (46) & 637 & (46) & & 605 & (45) & 563 & (43) & 57 & & (42) & 491 & (40) \\
\hline Stage & & & & & & & & & & & & & & \\
\hline Stage I & 429 & $(30)$ & 443 & (32) & & 133 & (32) & 479 & (36) & 49 & & (36) & 309 & (25) \\
\hline Stage II & 485 & (34) & 486 & (35) & & 141 & (33) & 433 & (33) & 42 & & (31) & 325 & (26) \\
\hline Stage III & 500 & (35) & 469 & (34) & & 179 & (35) & 407 & (31) & 44 & & (33) & 604 & (49) \\
\hline Histology & & & & & & & & & & & & & & \\
\hline Adenocarcinoma & 1274 & $(90)$ & 1217 & (87) & & 221 & $(90)$ & 1225 & (93) & & 66 & (93) & 1170 & (95) \\
\hline Mucinous adenocarcinoma & 127 & (9) & 173 & (12) & & 24 & (9) & 90 & (7) & 91 & & (7) & 65 & (5) \\
\hline Signet ring cell & 13 & (1) & 8 & (1) & 8 & 3 & (1) & 4 & (0) & 7 & & (1) & 3 & (0) \\
\hline Social economic status & & & & & & & & & & & & & & \\
\hline Low & 404 & (29) & 378 & (27) & & 177 & (35) & 487 & (37) & 40 & & (30) & 380 & (31) \\
\hline Medium & 628 & (44) & 623 & (45) & & 192 & (36) & 460 & (35) & 51 & & (38) & 520 & (42) \\
\hline High & 378 & (27) & 394 & (28) & & 379 & (28) & 370 & (28) & 44 & & (32) & 337 & (27) \\
\hline Unknown & 4 & (0) & 3 & (0) & 5 & 5 & (0) & 2 & (0) & 5 & & (0) & 1 & (0) \\
\hline (Neo)adjuvant radiotherapy & & & & & & & & & & & & & & \\
\hline Yes & 710 & $(50)$ & 773 & (55) & & 306 & $(60)$ & 817 & (62) & 67 & & (49) & 611 & (49) \\
\hline No & 704 & $(50)$ & 625 & (45) & & 547 & (40) & 502 & (38) & 68 & 9 & (51) & 627 & (51) \\
\hline
\end{tabular}




\begin{tabular}{|c|c|c|c|c|c|c|c|c|c|c|}
\hline & \multicolumn{10}{|c|}{ Period of diagnosis } \\
\hline & $2005-2006$ & $2007-2008$ & \multicolumn{2}{|c|}{$2009-2010$} & \multicolumn{2}{|c|}{$2011-2012$} & \multicolumn{2}{|c|}{$2013-2014$} & \multicolumn{2}{|c|}{$2015-2016$} \\
\hline \multicolumn{11}{|l|}{ Approach $^{\mathrm{b}}$} \\
\hline Laparoscopic surgery & & & 350 & $(26)$ & 544 & $(41)$ & 855 & $(63)$ & 978 & (79) \\
\hline Laparoscopic surgery with conversion & & & 91 & (7) & 140 & (11) & 128 & (9) & 93 & $(8)$ \\
\hline Open surgery & & & 902 & (67) & 617 & (47) & 366 & (27) & 167 & (13) \\
\hline Not applicable & & & 1 & $(0)$ & 4 & $(0)$ & 4 & $(0)$ & 0 & $(0)$ \\
\hline Unknown & & & 9 & (1) & 14 & (1) & 11 & (1) & 0 & $(0)$ \\
\hline
\end{tabular}

CRC, colorectal cancer.

Data are absolute numbers with percentages inside parentheses.

${ }^{a}$ Data was only available for colon cancer patients and from 2009 onward.

b Data was available from 2009 onward.

increase from $94.0 \%$ to $98.4 \%$ for those with colon cancer and from $93.9 \%$ to $99.9 \%$ for those with rectal cancer was seen (Fig. 2B).

When not only the acute but also the subacute postoperative mortality (within 90 days) was excluded, the increase in survival of the older patients between 2005 and 2016 was less pronounced than for the 30-day conditional survival (Fig. 2C).

\subsection{Resection rates}

Resection rates decreased significantly over time ( $\mathrm{p}<0.001)$ for both colon and rectal cancer as well as for younger and older patients (Fig. 3). For rectal cancer patients, a larger decrease in resection rates can be seen compared with colon cancer patients, especially in the older ( $>75$ years) patients for whom we found a decrease from $89.6 \%$ to $66.2 \%$ ( $<<0.001)$.

Supplementary figure 1 shows trends in resection rates for both colon and rectal cancer patients, stratified according to age and the presence of comorbidities. For younger colon cancer patients, resection rates decreased with $6.9 \%$ for patients without comorbidities compared with $8.2 \%$ for patients with comorbidities. For older colon cancer patients, the resection rates decreased with $9.8 \%$ for patients without comorbidities compared with

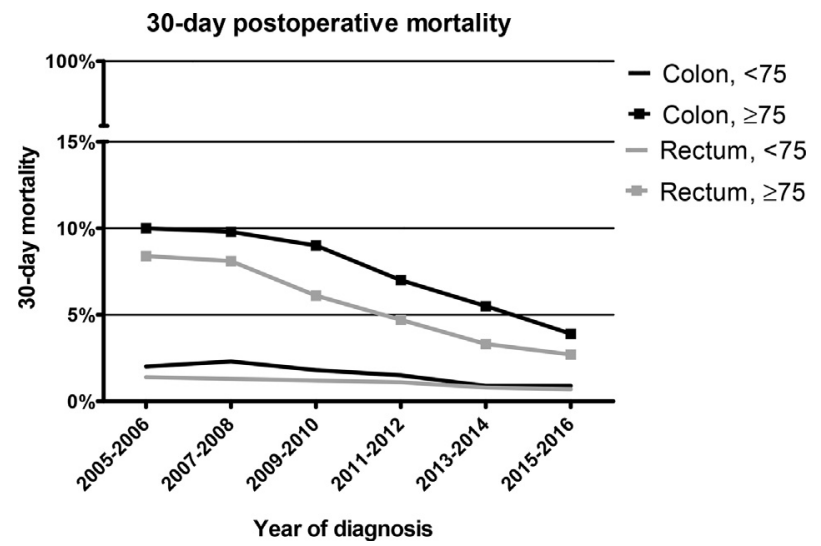

Fig. 1. 30-day postoperative mortality for stage I-III colon and rectal cancer patients, according to age $(<75, \geq 75)$.
$7.9 \%$ for patients with comorbidities. For younger rectal cancer patients, resection rates decreased more, with $14.1 \%$ for patients without comorbidities compared with $17.6 \%$ for patients with comorbidities. For older patients, this was slightly more pronounced with a decrease of $18.9 \%$ for patients without comorbidities compared with $24.8 \%$ for patients with comorbidities.

\section{Discussion}

This large population-based study demonstrates a significant decrease in postoperative colorectal cancer mortality between 2005 and 2016, especially for older patients: 30 -day mortality rates decreased from $10.0 \%$ to $4.0 \%$ for colon cancer patients and from $8.3 \%$ to $2.7 \%$ for rectal cancer patients. Compared with younger patients with stage I-III colorectal cancer, 1-year RS and 1year RS on the condition that patients survived the first 30 postoperative days are almost equal and equal for older patients with stage I-III colorectal cancer, respectively.

Decreased mortality rates are most likely because of quality and safety improvements in colorectal cancer care, with more standardised operation procedures and an increasing proportion of laparoscopic procedures $[16,17]$. Although it can be argued that better patient selection over time could also play a role in the lower mortality rates, it is unlikely that it is the main cause. This notion is based on the Supplementary figure, showing equal resection rates over time for colon cancer patients with and without comorbidities. For rectal cancer, resection rates for older patients with comorbidity decreased with $6 \%$ more compared with those without comorbidity which could be considered as patient selection. However, for younger rectal cancer patients, this trend was also evident with a $3.5 \%$ larger decrease in resection rates for patients with comorbidities. Therefore, it is unlikely that better patient selection can fully explain the catch-up of older CRC patients with younger CRC patients regarding postoperative mortality. A previous study that used data from the Dutch Surgical Colorectal Audit also showed nearly equal proportions of surgically treated CRC patients 
Table 2

Logistic regression analyses for 30-day, 90-day and 1-year postoperative mortality among stage I-III CRC, stratified according to tumour location (colon, rectum) and age $(<75, \geq 75)$.

\begin{tabular}{|c|c|c|c|c|c|c|c|c|c|c|}
\hline \multirow[t]{2}{*}{ Patient/tumour characteristics } & \multirow[t]{2}{*}{$\mathrm{N}$ (total) } & \multicolumn{3}{|c|}{ 30-day mortality } & \multicolumn{3}{|c|}{ 90-day mortality } & \multicolumn{3}{|c|}{ 1-year mortality } \\
\hline & & Crude \% & OR & $95 \%-\mathrm{CI}$ & Crude $\%$ & OR & $95 \%-\mathrm{CI}$ & Crude \% & OR & $95 \%-\mathrm{CI}$ \\
\hline \multicolumn{11}{|l|}{ Colon carcinoma, $<75$ years } \\
\hline \multicolumn{11}{|l|}{ Period of diagnosis } \\
\hline $2005-2006$ & 5718 & 2.0 & 1.00 & & 3.3 & 1.00 & & 7.6 & 1.00 & \\
\hline $2007-2008$ & 6014 & 2.3 & 1.20 & $(0.93-1.55)$ & 3.5 & 1.07 & $(0.87-1.32)$ & 7.0 & 0.91 & $(0.78-1.05)$ \\
\hline $2009-2010$ & 6401 & 1.8 & 0.94 & $(0.72-1.23)$ & 2.9 & 0.91 & $(0.74-1.13)$ & 6.2 & 0.81 & $(0.70-0.94)$ \\
\hline 2011-2012 & 6961 & 1.5 & 0.79 & $(0.60-1.03)$ & 2.3 & 0.72 & $(0.58-0.90)$ & 5.4 & 0.70 & $(0.61-0.81)$ \\
\hline $2013-2014$ & 7506 & 0.9 & 0.50 & $(0.37-0.67)$ & 1.6 & 0.51 & $(0.40-0.64)$ & 4.7 & 0.62 & $(0.53-0.72)$ \\
\hline $2015-2016$ & 10,085 & 0.9 & 0.48 & $(0.36-0.64)$ & 1.5 & 0.48 & $(0.38-0.60)$ & 3.4 & 0.47 & $(0.40-0.54)$ \\
\hline \multicolumn{11}{|l|}{ Colon carcinoma, $>75$ years } \\
\hline \multicolumn{11}{|l|}{ Period of diagnosis } \\
\hline $2005-2006$ & 4000 & 10.0 & 1.00 & & 13.8 & 1.00 & & 22.0 & 1.00 & \\
\hline $2007-2008$ & 4464 & 9.8 & 0.98 & $(0.85-1.14)$ & 13.1 & 0.95 & $(0.83-1.08)$ & 21.0 & 0.94 & $(0.84-1.04)$ \\
\hline $2009-2010$ & 4689 & 9.0 & 0.89 & $(0.78-1.03)$ & 11.9 & 0.85 & $(0.75-0.96)$ & 19.3 & 0.85 & $(0.76-0.94)$ \\
\hline 2011-2012 & 4794 & 7.0 & 0.68 & $(0.58-0.79)$ & 9.4 & 0.66 & $(0.57-0.75)$ & 16.5 & 0.70 & $(0.63-0.78)$ \\
\hline 2013-2014 & 5168 & 5.5 & 0.54 & $(0.46-0.63)$ & 7.3 & 0.51 & $(0.44-0.59)$ & 13.3 & 0.56 & $(0.50-0.62)$ \\
\hline $2015-2016$ & 4809 & 4.0 & 0.38 & $(0.32-0.46)$ & 5.5 & 0.37 & $(0.32-0.43)$ & 11.6 & 0.47 & $(0.42-0.53)$ \\
\hline \multicolumn{11}{|l|}{ Rectal carcinoma, $<75$ years } \\
\hline \multicolumn{11}{|l|}{ Period of diagnosis } \\
\hline $2005-2006$ & 3521 & 1.4 & 1.00 & & 2.3 & 1.00 & & 5.1 & 1.00 & \\
\hline $2007-2008$ & 3616 & 1.3 & 0.95 & $(0.64-1.43)$ & 2.2 & 0.97 & $(0.71-1.33)$ & 4.9 & 0.95 & $(0.77-1.18)$ \\
\hline $2009-2010$ & 3441 & 1.2 & 0.86 & $(0.57-1.31)$ & 1.7 & 0.74 & $(0.53-1.04)$ & 4.6 & 0.89 & $(0.71-1.11)$ \\
\hline $2011-2012$ & 3508 & 1.1 & 0.80 & $(0.52-1.22)$ & 1.7 & 0.72 & $(0.51-1.02)$ & 4.2 & 0.82 & $(0.66-1.03)$ \\
\hline 2013-2014 & 3538 & 0.8 & 0.53 & $(0.34-0.67)$ & 1.5 & 0.67 & $(0.47-0.95)$ & 3.5 & 0.68 & $(0.53-0.86)$ \\
\hline 2015-2016 & 4421 & 0.7 & 0.50 & $(0.32-0.79)$ & 1.0 & 0.40 & $(0.27-0.58)$ & 2.4 & 0.43 & $(0.33-0.55)$ \\
\hline \multicolumn{11}{|l|}{ Rectal carcinoma, $>75$ years } \\
\hline \multicolumn{11}{|l|}{ Period of diagnosis } \\
\hline $2005-2006$ & 1414 & 8.3 & 1.00 & & 11.7 & 1.00 & & 20.2 & 1.00 & \\
\hline $2007-2008$ & 1398 & 8.2 & 0.99 & $(0.75-1.29)$ & 12.2 & 1.06 & $(0.84-1.34)$ & 19.3 & 0.96 & $(0.80-1.16)$ \\
\hline $2009-2010$ & 1353 & 6.1 & 0.73 & $(0.54-0.97)$ & 8.9 & 0.74 & $(0.58-0.95)$ & 14.5 & 0.68 & $(0.56-0.83)$ \\
\hline $2011-2012$ & 1319 & 4.7 & 0.56 & $(0.40-0.77)$ & 7.5 & 0.62 & $(0.48-0.81)$ & 14.5 & 0.70 & $(0.57-0.86)$ \\
\hline 2013-2014 & 1364 & 3.3 & 0.37 & $(0.26-0.53)$ & 5.9 & 0.47 & $(0.36-0.63)$ & 10.7 & 0.48 & $(0.39-0.60)$ \\
\hline 2015-2016 & 1238 & 2,7 & 0.30 & $(0.20-0.44)$ & 4.0 & 0.29 & $(0.21-0.41)$ & 8.1 & 0.33 & $(0.26-0.42)$ \\
\hline
\end{tabular}

OR, odds ratio; CI, confidence interval; CRC, colorectal cancer.

Variables included in the logistic regression analyses are period of diagnosis, gender, stage of the tumour, subsite of the tumour, histology, social economic status, (neo)adjuvant chemotherapy for colon and (neo)adjuvant radiotherapy for rectum.

OR's were regarderd as significant when the $95 \%$-CI did not include 1.00 .

with high comorbidity scores between 2009 and 2016 [18]. Furthermore, frailty screening is currently implemented only to a limited extent in the Netherlands and internationally [19].

Our results are in contrast with previous Dutch studies $[6,20]$, in which much higher mortality rates among older patients with rectal cancer compared with younger patients were reported. Unfortunately, there is no recent comparable evidence from other Western countries, because studies analysing both differences in postoperative mortality between older and younger patients, as well as trends over time, are very scarce. Those that do mention differences between older and younger patients are limited by reporting overall cancer mortality or including age only as a risk factor in their multivariable analysis $[21,22]$.

As mentioned by Speelman et al., there might be riskavoiding behaviour of clinicians and therefore the possibility that older patients are being undertreated at the moment [5]. In the present study, we noticed decreasing resection rates over time with age-related disparities. Patients aged 75 years and older had a more pronounced decrease in resection rates, mainly when they had rectal cancer $(89.6 \%$ in $2005,66.2 \%$ in 2016$)$. In contrast, in a Dutch cohort diagnosed between 1995 and 2004, almost all patients with stage I-III colon or rectal cancer underwent surgery $(92-99 \%)$, regardless of age [23]. The decreasing resection rates in the current study are in accordance with more recent studies and could be because of the availability of other non-surgical treatment options, such as radiotherapy. Also, the Dutch national screening program was introduced in 2014, leading to the earlier detection of CRC and an increase in the proportion of patients undergoing local excision. Because we excluded local excisions from our study, this could be an additional explanation for the decreasing resection rates in our study. However, rectal cancer curative surgery might be omitted too often, and instead palliative radiotherapy is proposed to older patients. One should bear in mind that age itself should not be 

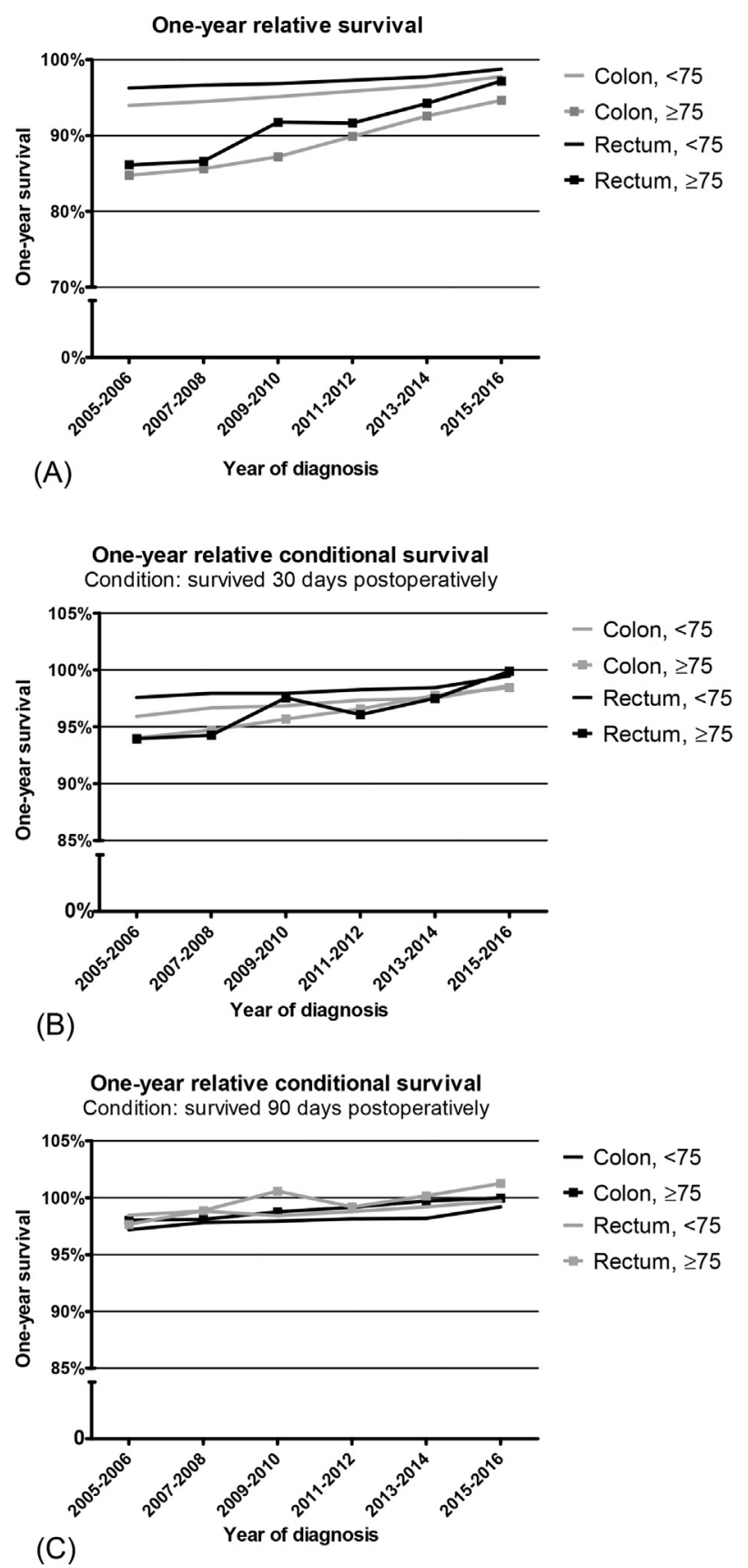

Fig. 2. One-year relative survival for stage I-III colon and rectal cancer patients, according to age $(<75, \geq 75)$. (A) Without any condition. (B) On the condition that patients survived the first 30 postoperative days. (C) On the condition that patients survived the first 90 postoperative days.

considered a risk factor for postoperative mortality [24]. Therefore, personalised strategies for older patients based on shared decision-making should be pursued after adequate frailty screening [25].

The need for adequate preoperative frailty screening is further emphasised by the knowledge that cancerrelated survival can be the same for older and younger patients, not only after 1-year survival as previously mentioned in the literature [26] but already after 30 days

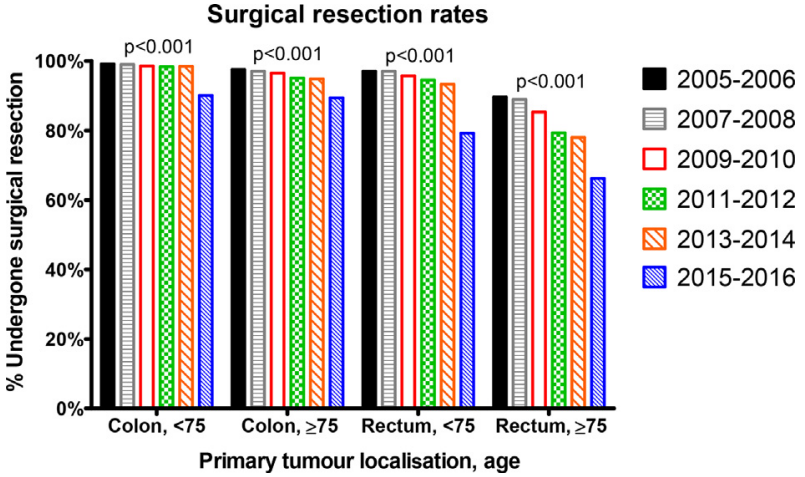

Fig. 3. Resection rates for stage I-III colon and rectal cancer patients, according to age $(<75, \geq 75)$ and period of diagnosis. Pvalues for trends over time are shown.

postoperative. This knowledge showcases the possible benefits of upcoming prehabilitation programs. These multidisciplinary programs, by reducing vulnerability and increasing resilience to postoperative risks, could enhance postoperative clinical outcomes and thereby lead to further survival improvement, especially for older, frail patients $[27,28]$.

The lack of complete and adequate information on comorbidity and of correction for emergency surgery are obvious limitations of this study, as both are associated with increased postoperative morbidity and mortality. Although the proportion of patients undergoing emergency surgery has remained stable over time and was fairly equal between older and younger patients, the impact of an emergency surgery is larger for older and multimorbid patients [29]. Not correcting for this factor could account for the remaining difference in mortality between older and younger patients.

Although we have seen an increase in survival rates, it is not clear what the impact of colorectal surgery is on postoperative functional outcomes. Older patients often give higher priority to these functional outcomes than to survival [30]. Further research should therefore focus not only on further increasing postoperative survival rates in older patients but also on quality of life and improvement of postoperative physical functioning. Prehabilitation programs could play a role in achieving this goal [31].

In conclusion, postoperative colorectal cancer mortality rates significantly decreased over time, especially for older patients with an almost equal 1-year RS compared with younger patients. Clinicians should bear in mind that previous literature is no longer representative of the current clinical practice when informing patients during shared decision making on surgical treatment. With adequate preoperative frailty screening and shared decision-making, there is no need for unnecessary risk-avoiding behaviour in older CRC patients. 


\section{Conflict of interest statement}

\section{None declared.}

\section{Funding}

This research did not receive any specific grant from funding agencies in the public, commercial or not-forprofit sectors.

\section{Appendix A. Supplementary data}

Supplementary data to this article can be found online at https://doi.org/10.1016/j.ejca.2019.04.036.

\section{References}

[1] Netherlands Cancer Registry. www.cijfersoverkanker.nl; 2019.

[2] Salive ME. Multimorbidity in older adults. Epidemiol Rev 2013; 35:75-83.

[3] Townsley CA, Selby R, Siu LL. Systematic review of barriers to the recruitment of older patients with cancer onto clinical trials. J Clin Oncol 2005;23(13):3112-24.

[4] Egenvall M, Schubert Samuelsson K, Klarin I, et al. Management of colon cancer in the elderly: a population-based study. Colorectal Dis : the Off J Assoc Coloproctol G B Irel 2014;16(6): 433-41.

[5] Speelman AD, van Gestel YR, Rutten HJ, de Hingh IH, Lemmens VE. Changes in gastrointestinal cancer resection rates. Br J Surg 2015;102(9):1114-22.

[6] Rutten HJ, den Dulk M, Lemmens VE, van de Velde CJ, Marijnen CA. Controversies of total mesorectal excision for rectal cancer in elderly patients. Lancet Oncol 2008;9(5):494-501.

[7] Biondi A, Vacante M, Ambrosino I, Cristaldi E, Pietrapertosa G, Basile F. Role of surgery for colorectal cancer in the elderly. World J Gastrointest Surg 2016;8(9):606-13.

[8] Ugolini G, Ghignone F, Zattoni D, Veronese G, Montroni I. Personalized surgical management of colorectal cancer in elderly population. World J Gastroenterol 2014;20(14):3762-77.

[9] Papamichael D, Audisio RA, Glimelius B, et al. Treatment of colorectal cancer in older patients: International Society of Geriatric Oncology (SIOG) consensus recommendations 2013. Ann Oncol 2015;26(3):463-76.

[10] Fritz A, Percy C, Jack A, et al. International classification of diseases for oncology (ICD-O). Geneva: World Health Organization; 2000.

[11] Wittekind CGF, Hutter R, Klimpfinger MLS. TNM atlas. Berlin: Springer-Verslag; 2004.

[12] Barnett K, Mercer SW, Norbury M, Watt G, Wyke S, Guthrie B. Epidemiology of multimorbidity and implications for health care, research, and medical education: a cross-sectional study. Lancet 2012;380(9836):37-43.

[13] van Oostrom SH, Picavet HS, van Gelder BM, et al. [Multimorbidity and comorbidity in the Dutch population-data from general practices]. Ned Tijdschr Geneeskd 2011;155:A3193.

[14] Gooiker GA, Dekker JW, Bastiaannet E, et al. Risk factors for excess mortality in the first year after curative surgery for colorectal cancer. Ann Surg Oncol 2012;19(8):2428-34.
[15] CBS Nederland. Population. 2018. https://www.cbs.nl/en-gb/ society/population.

[16] Ljungqvist O, Scott M, Fearon KC. Enhanced recovery after surgery: a review. JAMA Surgery 2017;152(3):292-8.

[17] Hamaker ME, Schiphorst AH, Verweij NM, Pronk A. Improved survival for older patients undergoing surgery for colorectal cancer between 2008 and 2011. Int J Colorectal Dis 2014;29(10): 1231-6.

[18] de Neree Tot Babberich MPM, Detering R, Dekker JWT, et al. Achievements in colorectal cancer care during 8 years of auditing in The Netherlands. Eur J Surg Oncol 2018;44(9):1361-70.

[19] Ghignone F, van Leeuwen BL, Montroni I, et al. The assessment and management of older cancer patients: a SIOG surgical task force survey on surgeons' attitudes. Eur J Surg Oncol 2016;42(2): 297-302.

[20] Breugom AJ, Bastiaannet E, Dekker JWT, Wouters M, van de Velde CJH, Liefers GJ. Decrease in 30-day and one-year mortality over time in patients aged $>/=75$ years with stage I-III colon cancer: a population-based study. Eur J Surg Oncol 2018; 44(12):1889-93.

[21] Braendegaard Winther S, Baatrup G, Pfeiffer P, Qvortrup C. Trends in colorectal cancer in the elderly in Denmark, 1980-2012. Acta Oncol 2016;55(Suppl 1):29-39.

[22] Theile DE, Philpot S, Blake M, Harrington J, Youl PH. Outcomes following colorectal cancer surgery: results from a population-based study in Queensland, Australia, using quality indicators. J Eval Clin Pract 2018:1-9.

[23] Janssen-Heijnen MLG, Maas HAAM, Houterman S, Lemmens VEPP, Rutten HJT, Coebergh JWW. Comorbidity in older surgical cancer patients: influence on patient care and outcome. Eur J Cancer 2007;43(15):2179-93.

[24] Khan MR, Bari H, Zafar SN, Raza SA. Impact of age on outcome after colorectal cancer surgery in the elderly - a developing country perspective. BMC Surg 2011;11:17.

[25] Montroni I, Ugolini G, Saur NM, et al. Personalized management of elderly patients with rectal cancer: expert recommendations of the european society of surgical oncology, european society of coloproctology, international society of geriatric oncology, and American college of surgeons commission on cancer. Eur J Surg Oncol : J Eur Soc Surg Oncol Br Assoc Surg Oncol 2018;44(11): $1685-702$.

[26] Dekker JW, van den Broek CB, Bastiaannet E, van de Geest LG, Tollenaar RA, Liefers GJ. Importance of the first postoperative year in the prognosis of elderly colorectal cancer patients. Ann Surg Oncol 2011;18(6):1533-9.

[27] Barberan-Garcia A, Ubre M, Roca J, et al. Personalised prehabilitation in high-risk patients undergoing elective major abdominal surgery: a randomized blinded controlled trial. Ann Surg 2018;267(1):50-6.

[28] Gurlit S, Gogol M. Prehabilitation is better than cure. Curr Opin Anaesthesiol 2018;32(1):108-15.

[29] Kolfschoten NE, Wouters MW, Gooiker GA, et al. Nonelective colon cancer resections in elderly patients: results from the Dutch surgical colorectal audit. Dig Surg 2012;29(5):412-9.

[30] Akishita M, Ishii S, Kojima T, et al. Priorities of health care outcomes for the elderly. J Am Med Dir Assoc 2013;14(7): 479-84.

[31] Minnella EM, Bousquet-Dion G, Awasthi R, ScheedeBergdahl C, Carli F. Multimodal prehabilitation improves functional capacity before and after colorectal surgery for cancer: a five-year research experience. Acta Oncol (Stockh) 2017;56(2): $295-300$. 